Michał Wojciechowski

UWM, Olsztyn

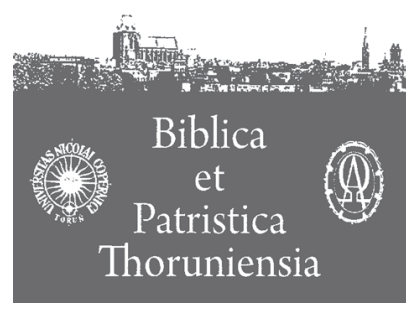

5 (2012) ISSN 1689-5150

\title{
Wpływy greckie w Apokalipsie św. Jana
}

\section{Greek influences in the Revelation of John}

Słowa klucze: Apokalipsa, hellenizacja chrześcijaństwa, wpływy greckie w Biblii, apokaliptyka, mitologia.

Key words: Revelation of John, hellenisation of Christianity, Greek influences in the Bible, apocalypticism, mythology.

$\mathrm{Z}$ agadnienie wpływów greckich w księgach biblijnych należy do podstawowych kwestii historycznych podejmowanych przy egzegezie. Jednocześnie jest to kwestia często zaniedbywana. Można bowiem zauważyć, że wiele prac z dziedziny biblistyki ją pomija. Wtedy kwestia takich wpływów kojarzona jest dopiero z rozwojem chrześcijaństwa w świecie grecko-rzymskim ${ }^{1}$.

Przyczyny mogą być różne. Z motywów teologicznych skupiają się autorzy na kwestiach wewnątrzbiblijnych. Uwzględniając tło bliskowschodnie Starego Testamentu czy żydowskie Nowego Testamentu, pomniejsza się wpływ otoczenia greckiego. Metody literackie skłaniają do studiowania tekstu samego w sobie i odczytywania jego przesłania głównie w aspekcie narracyjnym czy retorycznym.

1 Związane to było w nowszych czasach z tezami A. Harnacka o wtórnej hellenizacji chrześcijaństwa; zob. omówienia: J. Hessen, Griechische oder biblische Theologie? Das Problem der Hellenisierung des Christentums in neuer Beleuchtung, wyd. 2, München 1962; H.D. Betz, The Birth of Christianity as a Hellenistic Religion: Three Theories of Origin, „Journal of Religion" 74 (1994), s. 1-25; L. Scheffczyk, Tendenzen und Brennpunkte der neueren Problematik um die Hellenisierung des Christentums, München 1982. W tym kierunku prowadził też zapoczątkowany przez F. Dölgera nurt badawczy „Antike und Christentum”, por. np. C. Andresen, Antike und Christentum, „Theologische Realenzyklopädie”, t. 3, 1978, s. 5099; E.A. Judge, 'Antike und Christentum': Towards a Definition of the Field. A Bibliographical Study, ANRW II/23.1, Berlin-New York 1979, s. 3-58; także w szerszej perspektywie H.-D. Betz, Antiquity and Christianity, JBL 117 (1998)1, s. 3-23. 
Z drugiej strony studia nad wpływami greckimi popadały czasem w przesadę, jak w nurcie Religionsgeschichte ${ }^{2}$. Niemniej jednak, nie podejmując tez skrajnych, badania nowsze doprowadziły do nagromadzenia bogatych danych na temat wpływu kultury greckiej na świat biblijny, a więc na późniejsze księgi Starego Testamentu, na judaizm starożytny i na Nowy Testament. Wyrażają się one między innymi w zbiorach tekstów paralelnych ${ }^{3}$ oraz w opracowaniach zagadnień cząstkowych ${ }^{4}$.

Można wstępnie zauważyć, że wpływ ten bynajmniej nie ogranicza się do używanie języka greckiego. Jest bardzo silny w sferze gatunku literackiego i generalnie form literackich ${ }^{5}$. Obejmuje selektywne wykorzystanie obrazów, motywów i terminów podsuniętych przez świat grecki, a także z greckich idei moralnych i antropologicznych. Natomiast trudno go znaleźć w biblijnej koncepcji Boga i świata. Podobnie było w zhellenizowanym judaizmie epoki zwanej międzytestamentalną ${ }^{6}$.

Od strony metodycznej, oczywistą trudnością jest rozróżnienie między podobieństwami a zależnościami. Jeśli jednak dany motyw nie jest poświadczony w Biblii Hebrajskiej i na starożytnym Wschodzie, a znamy go ze świata grec-

2 Zob. jej podsumowania odnośnie do NT: C. Clemen, Religionsgeschichtliche Erklärung des Neuen Testaments, Berlin 1924; P. Wendland, Die hellenistisch-römische Kultur in ihren Beziehungen zum Judentum und Christentum, Handbuch zum Neuen Testament 2, wyd. 4 zmienione, Tübingen 1972.

3 Najszersza jest nieukończona seria: Neuer Wettstein. Texte zum neuen Testament aus Griechentum und Hellenismus, 3 t., Berlin 2001-. Zob. krótsze zestawienia: Hellenistic Commentary to the New Testament, (znacznie poszerzone względem wyd. niem. Religionsgeschichtliches Textbuch zum Neuen Testament, Göttingen 1987); C.K. Barrett (red.), The New Testament Background. Writings from Ancient Greece and the Roman Empire That Illuminate Christian Origins, London 1987.

4 Np. A.J. Malherbe, Hellenistic Moralists and the New Testament, ANRW II/26.1 (1992), s. 267-333; M.L. Colish, Stoicism and the New Testament, ANRW II/26.1 (1992), 334-379 (historia badań nad tym tematem, a nie synteza); G. E. Sterling, Hellenistic Philosophy and the New Testament, w: Handbook to Exegesis of the New Testament, S.E. Porter (red.), New Testament Tools and Studies 25, s. 313-358.

5 Dla NT: D.E. Aune, The New Testament in Its Literary Environment, Cambridge 1988; K. Berger, Hellenistische Gattungen in Neuen Testament, ANRW II/25.2 (1984): 1031-1432, 1832-1885; D. Dormeyer, Das Neue Testament im Rahmen der antiken Literaturgeschichte, Darmstadt 1993.

6 Zob. zwł. M. Hengel, Judentum und Hellenismus, wyd. 2, Tübingen 1973 (przekład ang. z 1974, Judaism and Hellenism); V. Tcherikover, Hellenistic Civilization and the Jews, Philadelphia 1959; L.H. Feldman, Jew and Gentile in the Ancient World, Princeton 1996; J.J. Collins, Between Athens and Jerusalem, wyd. 2, Grand Rapids 2000; zob. T. Zieliński, Hellenizm a judaizm, Warszawa 1927 (wyd. nowe Toruń 2001); J. Melèze Modrzejewski, Żydzi nad Nilem od Ramzesa II do Hadriana, Kraków 2000. 
kiego, zależność jest prawdopodobna. Od bezpośrednich zapożyczeń należy odróżnić pośrednie, na przykład motywy przyswojone z kultury greckiej w judaizmie hellenistycznym, a $\mathrm{z}$ niego przejęte przez Nowy Testament. Judaizm starożytny już uległ w znacznym stopniu wpływom greckim, nawet jeśli ich dokładny zasięg jest przedmiotem dyskusji.

W przypadku Apokalipsy jest ona odczytywana przede wszystkim na tle Starego Testamentu, jako że około połowy jej tekstu stanowią aluzje do niego ${ }^{7}$. Druga inspiracja to apokaliptyka żydowska, po części zaginiona. Ta jednak korzystała już z kultury greckiej, co da się wykryć w gatunku i obrazach Księgi Daniela ${ }^{8}$, szeroko w Apokalipsie wykorzystywanej. Oznacza to przynajmniej pośredni wpływ kultury greckiej.

Nie należy też wykluczać wpływu bezpośredniego, zwłaszcza w sferze wykorzystania symboliki mitycznej w wizjach Apokalipsy, oraz nawiązań do znanych autorowi greckich obrazów i sposobów mówienia. Większość komentatorów pomija jednak ten aspekt. Bogaty materiał w postaci paralel greckich gromadzi największy komentarz do Apokalipsy, pióra D.E. Aune ${ }^{9}$, ale przeważają tam paralele drugo- i trzeciorzędne, co wymaga selekcji; brak też uogólnienia. Artykuł poświęcony wprost greckim wpływom w Apokalipsie pozostaje wyjątkiem $^{10}$.

\section{Gatunek}

Gatunek literacki Apokalipsy św. Jana nawiązuje niewątpliwie do apokaliptyki, jaką znamy z Księgi Daniela i z apokryfów Starego Testamentu. Ten jednak gatunek inspirował się greckimi wzorami co do proroctw i wizji, wykorzystując obrazy z mitów i orientując się na przepowiadanie przyszłości ${ }^{11}$. Apokaliptyka przechodzi też od postrzegania proroctwa jako natchnionego głosu Bożego

7 Najpełniej komentarz: G.K. Beale, The Book of Revelation (New International Greek Testament Commentary), Grand Rapids-Carlisle 1999.

8 K. Kiejdo, Księga Daniela jako przykład hellenistycznych wpływów na kulturę Izraela, diss. Wydział Teologii UWM, Olsztyn 2011.

9 D.E. Aune, Revelation, t. 1-3, Word Biblical Commentary 52A-C, Dallas 1997-1998. Stale go w tym artykule wykorzystuję.

10 O. Böcher, Hellenistisches in der Apokalypse des Johannes, w: Geschichte - Tradition Reflexion, Fs. M. Hengel, t. 3, red. H. Lichtenberger, Tübingen 1996, s. 473-492; z niego też skorzystam kilkakrotnie.

11 Ogólnie o apokaliptyce np.: D. Hellholm (red.), Apocalypticism in the Mediterranean World and the Near East. Proceedings of the International Colloquium on Apocalypticism (Uppsala 1979), Tübingen 1983; J.J. Collins, The Apocalyptic Imagination. An Introduction to 
rzecznika do interpretowania go, w duchu grecko-rzymskim, jako przepowiadania przyszłości, z elementem ekstazy i cudownych doznań.

Można przyjąć, że tego rodzaju wpływ grecki w przypadku Apokalipsy nie był bezpośredni, gdyż mogła ona po prostu naśladować wzory już przyjęte w judaizmie. Nie jest to jednak do końca prawdą, gdyż w wizjach Apokalipsy znajdziemy także obrazy wzięte $\mathrm{z}$ mitologii, a w judaizmie niepoświadczone. Tak czy inaczej, księga zawiera elementy pokrewne względem pogańskich wyroczni, proroctw i znaków od bóstw. Miały one wpływ na sprawy życiowe, a także polityczne $^{12}$. Wyroczni bowiem oczekiwano. Z kolei wykorzystaniu motywów mitycznych sprzyjał ich charakter symboliczny. Służą one za materiał literacki, wywarły więc pewien wpływ, ale ich wykorzystanie jest podporządkowane koncepcji całości.

\section{Greckie zwroty, obrazy i symbole}

Omówmy teraz przykłady szczegółowe ${ }^{13}$. Potrójne określenie bytu boskiego jako tego, który istnieje w każdym czasie, „który jest, był i przychodzi” (Ap 1, 4.8 itd.), ma wyraźną inspirację grecką. Już w prologu Teogonii Hezjoda (33-34) mowa o Muzach: „Nakazały opiewać ród szczęsnych zawsze żyjących oraz je same zawsze: i na początku, i z końcem”. Tekst orficki głosi, że Zeus jest głową i środkiem, że spełni wszystko (fragment orficki 21a, Kern). Platon, mówiąc o częściach czasu, stwierdza, że: „odnosimy je do istoty wiecznej i mówimy, że była, jest i będzie" (Timajos 37E, zacytowane już u Ireneusza, Adversus haereses 3,25,5; por. Prawa 4, 715E). Plutarch przytacza inskrypcję na posągu Ateny/ Izydy: „Ja jestem wszystkim, co istniało, istnieje i ma istnieć” (O Izydzie i Ozyrysie, Moralia 354C). Pauzaniasz cytuje heksametr kapłanek Zeusa z Dodony: „Zeus był, Zeus jest, Zeus będzie, o wielki Zeusie!” (Wędrówki po Helladzie 10,12,10). W pismach hermetycznych: „Bóg wieczny [...] to ten, który jest, który był i który zawsze będzie" (Pseudo-Apulejusz, Asklepios łac., 2,313). Apokalipsa stosuje to do Boga Biblii, wszelako z odcieniem dynamicznym, a nie ontologicznym, gdyż zamiast tego, który będzie, występuje Przychodzący.

the Jewish Matrix of Christianity, New York 1984; wyd. 2, 1998; M. Wolter, Apokalyptik als Redeform im Neuen Testament, NTS 51 (2005), s. 171-191.

12 Np. P. de Villiers, Oracles and Prophecies in the Graeco-Roman World and the Book of Revelation in the New Testament, APB 8 (1997), s. 79-96.

13 W tej prezentacji korzystam, aczkolwiek z uzupełnieniami i skrótami, z urywków mojego komentarza: M. Wojciechowski, Apokalipsa św. Jana, Nowy Komentarz Biblijny. Nowy Testament 20, Częstochowa 2012. 
Wizja Chrystusa w Ap 1,12-20 nawiązuje do Syna Człowieczego z Dn 7,9.13; 10,5-6. jednocześnie jej elementy pokrywają się z ikonografią Heliosa (blask, gwiazdy), którą zawłaszczali też cesarze. Na aureusie na cześć Domicji Longiny z 83/84 r. figuruje książę z siedmioma gwiazdami.

W Ap 1,18 obraz kluczy w boskim ręku wydaje się pochodzenia greckiego. Pluton miał mieć klucze Hadesu (Pauzaniasz, Wędrówki po Helladzie 5,20,3); tak samo jeden $\mathrm{z}$ trzech podziemnych sędziów Ajakos (Apollodor z Aten, Biblioteka 3,12,6 $\mathrm{i}$ in.). Utożsamiana $\mathrm{z}$ różnymi boginiami Hekate miała klucze całego świata (Hymny orfickie 1,7 z II w.) i nosiła przydomek „klucznicy”. Innym bóstwom też przypisywano rozmaite klucze. Wtórnie o boskich kluczach mówią teksty rabiniczne.

Ap 1,20 i sąsiednie nawiązują do symboliki astralnej. Filon z Aleksandrii twierdzi wprost, że siedem lamp menory symbolizuje siedem ciał niebieskich (Kto jest dziedzicem boskich dóbr 221-222). Klemens z Aleksandrii porównał lampy menory z jaśniejącymi planetami ze słońcem w centrum (Kobierce 5,6). Utożsamienie aniołów z gwiazdami ma za tło kosmologiczne poglądy starożytne, według których ciała niebieskie były boskie, albo też kierowały nimi niebiańskie inteligencje. Choć Biblia odrzuca astrologię i ubóstwianie ciał niebieskich, tu najwyraźniej nawiązano do skojarzeń potocznych. Zaznaczmy, że przyswojenie motywów astralnych i astrologicznych mogło się dokonać za pośrednictwem judaizmu ówczesnego, skoro są one obecne już w Księdze Daniela ${ }^{14}$.

W Ap 4-5 tło biblijne i bliskowschodnie sąsiaduje z greckim ${ }^{15}$. O potrójnej formule z Ap 4,8 była już mowa powyżej. Formuła hymniczna $\mathrm{z}$,godzien jest” (Ap 4,11; 5,9) odpowiada stylowi hołdów wobec cesarzy rzymskich. „Pan i Bóg" ma odpowiednik w tytulaturze Domicjana, Dominus et Deus (Swetoniusz, Żywoty Cezarów. Domicjan 12,1-2). Szaty starszych w Ap 4,4; 5,8; por. 7,9 , odpowiadają ówczesnej praktyce liturgicznej. Cztery istoty żywe kojarzono $\mathrm{z}$ gwiazdozbiorami.

Jedna z hipotez na temat liczby 666 w Ap 13,18 głosi, że wynikła ona z gematrii czyli izopsefii ${ }^{16}$. W starożytności nie używano osobnych znaków cyfrowych, a litery zastępowały cyfry. Po hebrajsku i grecku pierwsze litery alfabetu

14 K. Kiejdo, op. cit., s. 129-135; 162-168.

15 R. Morton, Glory to the God and to the Lamb: John's Use of Jewish and Hellenistic/ Roman Themes in Formatting his Theology in Revelation 4-5, JSNT 83 (2001), s. 89-109.

16 Przyjęte w komentarzach, na temat genezy zob. J. Chopineau, La Bible symbolique: note sur l’apport hellénistique à la numérologie symbolique de la Bible, „Analecta Bruxellensia" 1 (1996), s. 88-101. 
reprezentowały kolejno 1, 2, 3 itd. Następnie szło 10, 20, 30..., wreszcie 100, 200, 300... Sumowanie wartości liczbowych liter w słowie i odczytywania go jako liczby było więc dość często praktykowane i spotyka się je w Biblii. Na przykład w Mt 1,17 liczba 14 reprezentuje Dawida, gdyż hebrajskie spółgłoski w jego imieniu, DWD (samogłosek nie notowano) odpowiadają liczbie $14(4+6+4)$. To pokazuje, że judaizm już $\mathrm{w}$ tych czasach przyswoił tego typu spekulacje.

Takich wyjaśnień dla 666 podano mnogość, ale przeważnie są one zupełnie fantazyjne. Godne uwagi są trzy: a) Jedna z transkrypcji słów „Cesarz Neron” z greckiego na aramejski brzmiałaby QSR NRWN (קרר נרון). Wartość liczbowa tej sekwencji wynosi właśnie $666(100+60+200,50+200+6+50)$. Bez końcowego $N$ (czyli w zgodzie z wersją łacińską Nero) mamy 616, liczbę spotykaną w części rękopisów. b) Wartość liczbową 666 ma po grecku zdanie „Cezar nowy bóg": kaisar theos neos. Bez neos mamy też 616. c) Greckie thērion z Apokalipsy, „potwór, bestia” po aramejsku brzmi TRJWN (תריון), dając również sumę $666(400+200+10+6+50)$. Niemniej jednak liczba 666 może pochodzić po prostu z $1 \mathrm{Krl}$ 10,14 (tak komentarz Bedy). Oznacza tam ona ogromną sumę 666 talentów, jakie ściągał z poddanych w podatkach król Salomon. Potworne państwo jest potwornym zdziercą.

\section{Inspiracje mitologiczne}

W Ap 6,8; 20,13-14 siły śmierci i podziemia są upersonifikowane. Tanatos i Hades wymieniani byli skądinąd wśród bogów. Upersonifikowane są gwiazdy (Ap 9,1). Odpowiada to greckiemu sposobowi myślenia. Cechy mityczne ma anioł zagłady z Ap 9,11. Anioł wód z Ap 16,4-7 łączyłby cechy z tradycji żydowskiej i mitologicznej ${ }^{17}$.

Akcję Ap 12 porównywano do różnych mitów, z początku do babilońskich (Gunkel) i egipskich (Bousset), a potem, trafniej, do greckich ${ }^{18}$. Chodzi o opo-

17 A. Yarbro Collins, The History-of-Religions Approach to Apocalypticism and the Angel of the Waters' (Rev. 16:4-7), CBQ 39 (1977), s. 367-381.

18 P. Busch, Der gefallene Drache. Mythenexegese am Beispiel von Apokalypse 12, Texte und Arbeiten zum neutestamentlichen Zeitalter 19, Tübingen 1996; M. Koch, Drachenkampf und Sonnenfrau. Zur Funktion des Mythischen in der Johannesapokalypse am Beispiel von Apk 12 (WUNT II/184), Tübingen 2004; J.W. van Henten, Dragon Myth and Imperial Ideology in Revelation 12-13, w: The Reality of Apocalypse, red. D.L. Barr, Atlanta 2006, s. 181-205; zob. pol. L. Stefaniak, Elementy judaistyczne i motywy hellenistyczne rozdziału XII Apokalipsy w świetle tekstów qumrańskich $i$ danych $z$ archeologii, diss. ATK, Warszawa 
wieść o narodzinach Apolla i Artemidy, być może pochodzącą z przedgreckiej Azji Mniejszej. Pyton ściga ciężarną Letę, która z pomocą boga Posejdona chroni się na Delos; po porodzie Apollo zabija Pytona (Lukan, Wojna domowa 5,79-81; Lukian, Dialogi zmartych 9; Hyginus, Fabulae 140). A chociaż kobieta w Ap 12 symbolizuje lud Boży, szukano też analogii do bogiń, choć nie wydają się one zbyt wyraźne ${ }^{19}$.

Ponieważ w Ap 12 centralnym motywem wizji jest walka, szukano źródeł literackich w mitach starożytnych, które często przedstawiają sceny bitewne i inne starcia ${ }^{20}$. Źródłem użytych obrazów byłyby zapewne rozmaite motywy obiegowe (analogicznie jak przy Rdz 1-11). W starożytnych mitach ścierały się siły dobra i zła: w Mezopotamii Marduk i Tiamat, w Egipcie Ozyrys i Set, w Grecji Zeus i tytani (o walce ze złem w życiu ludzkim zob. też mowę Agamemnona o działaniu Ate u Homera, Iliada 19,85nn). Miało to pewne odbicie w Biblii, w scenach walki Jahwe $\mathrm{z}$ chaosem oraz potworami (Rahab i Lewiatan).

W judaizmie późniejszym i wczesnym chrześcijaństwie pojawia się na tym tle motyw buntu aniołów i postać szatana jako wroga. Apokryficzna 1 Księga Henocha 6-11 nawiązując do Rdz 6,1-4 przedstawia grzech aniołów z kobietami (motyw skądinąd wzięty z mitów o niebianach płodzących dzieci); buntownicy zostają związani i uwięzieni. Upadłe anioły i ich wódz występują też w Księdze Jubileuszów. Diabeł okazuje się zarazem wrogiem wierzących (por. np. 1 P 5,8), zresztą właśnie ta jego cecha jest w Biblii uwypuklona.

Mimo drobniejszych różnic, podobieństwo samych obrazów do Ap 12 pozostaje znaczne. Natomiast kontekst jest inny. To podobieństwo i ta różnica oznacza, że mity dostarczyły tu materiału literackiego, ale nie inspiracji na poziomie treści. Biorąc pewne obrazy z mitów, autor przetwarza je, by

1970; E. Polaszek, Ślady greckiej tradycji w XII rozdziale Apokalipsy św. Jana, Nowy Filomata 1 (1997) 4, s. 252-257.

19 S. Benko, The Virgin Goddess. Studies in the Pagan and Christian Roots of Mariology, Studies in the History of Religions 59, Leiden 1993; R. Bergmeier, Altes und Neues zur „Sonnenfrau am Himmel“ (Apk 12). Religionsgeschichtliche und quellenkritische Beobachtungen zu Apk 12 1-17, ZNW 76 (1985), s. 225-242. Wcześniej T. Zieliński, Die griechischen Quellen der Apokalypse, „Forschungen und Fortschritte” 7 (1931), s. 155-156; por. tenże, Chrześcijaństwo antyczne, Toruń 1999, s. 85-106, o przedstawianiu Chrystusa za pomocą symboliki Apollina.

20 A. Yarbro Collins, The Combat Myth in the Book of Revelation, Harvard Dissertations in Religion 9, Missoula 1976; M. Karczewski, Między historia idei a oryginalnościa Ap 12 - w poszukiwaniu metody interpretacji, „Studia Elbląskie” 2 (2000), s. 219-236. 
powiedzieć coś innego. Jego wizja konkuruje z mitami ${ }^{21}$. Wizja symboliczna korzysta z mitologii, ale ma mit zdezaktualizować, wyprzeć i zastąpić (tak jak w Rdz 1-11) ${ }^{22}$.

Opis bestii w Ap 13 wzoruje się na Dn 7, dotyczy to zwłaszcza rogów. Zarazem zawiera wiele nawiązań do mitologii i religijności greckiej. Siedem głów to motyw mityczny, podobny do sześciogłowej Scylli z Homera (Odyseja 12, 90). Spotykamy go wtórnie także w apokryfach (Testament Abrahama 17,14 ; 19,6-7; Ody Salomona 22,5; por. Ps 74,14; Dn 7,6). Diadem to pospolity grecki symbol władzy królewskiej (wieńce z Ap 2,10; 3,11 kojarzą się natomiast nagrodami w zawodach sportowych). Zauważmy ponadto, iż epitet potwora czyli bestii, gr. thērion, stosowano do władców (por. np. Plutarch, Moralia 147b; Katon Starszy 8,13; Swetoniusz, Tyberiusz 24,1; obszernie Filostrates, Żywot Apolloniosa $z$ Tyany 4,38).

Od strony plastycznej opis potwora jest dość surrealistyczny i trudno go sobie wyobrazić. Kojarzy się z mitycznymi hybrydami zwierzęcymi. Takie hybrydy występują i gdzie indziej w Apokalipsie, a mianowicie w postaci czterech istot żywych, choć szczegóły ich wyglądu czerpią z Ezechiela (Ap 4,6-8).

Za inspirację wzmianki o uleczeniu śmiertelnej rany potwora uchodzi krążąca wówczas legenda o Nero redivivus (Nero redux), powrocie do życia cesarza Nerona; relacjonuje ją m.in. Dio Chryzostom (Mowa 21,10) i apokryficzne Wyrocznie Sybilli (4,138-139 i in.). Neron w obliczu klęski w wojnie ze zbuntowanymi popełnił samobójstwo Rozchodziły się jednak plotki o ucieczce Nerona do kraju Partów. Pojawiali się samozwańcy, podszywający się pod Nerona, przynajmniej dwóch, i zyskiwali zwolenników (Tacyt, Dzieje 2,8; Dio Kasjusz 66,19,3). Domicjan uchodził za nowego Nerona (Juwenalis, Satyry 4,38).

Inspiracją mogłyby też być zabobonne pogłoski o poruszających się czy mówiących posągach (np. Plutarch, Moralia 397E-398B; Lukian, De dea Syra 10; Atenagoras, Prośba za chrześcijanami 18; Kasjusz Dion 41, 61; 54,7; Dionizy z Halikarnasu, Antiquitates romanae 8,56,2). W formie baśniowej ożywienie posągu występuje w micie o Pigmalionie i Galatei. Charakter satyryczny ma wzmianka Swetoniusza, że Zeus z Olimpii roześmiał się w głos, gdy na rozkaz Kaliguli przybyli robotnicy, by go rozebrać i zawieźć do Rzymu (Gajusz 57,1). Stosowano magiczne zabiegi zmierzające do uzyskania od posągów wyroczni.

21 S. Schreiber, Die Sternenfrau und ihre Kinder (Offb 12). Zur Wiederentdeckung eines Mythos, NTS 53 (2007) 3, s. 436-457.

22 Wykorzystanie mitów w Księdze Rodzaju i w Apokalipsie wydaje się metodycznie podobne. Niezbadanie tej kwestii jest słabym punktem cennej monografii M. Karczewskiego, Reinterpretacja Księgi Rodzaju w Apokalipsie św. Jana, Olsztyn 2010. 
Trzystopniowa budowa świata występuje w Ap 5,13 i gdzie indziej (niebo, ziemia, podziemie). Odpowiada to popularnemu obrazowi świata w tej epoce. W Ap 16 pojawiają się natomiast, choć w formie nieuporządkowanej, cztery żywioły tradycji greckiej: ziemia, woda, ogień i powietrze (uzupełnione o istotne dla autora Apokalipsy motywy polityczne). Te skojarzenia nie kłócą się z zależnością od listy plag egipskich. Te bowiem wiązały się ze zjawiskami przyrody i już w tradycji żydowskiej były kojarzone z żywiołami (Filon, Życie Mojżesza 96-146; po części Mdr 12nn). Ap 16,13-14 dodaje w greckiej konwencji wrzaskliwe i nieczyste żaby ${ }^{23}$.

Prostytucję w Ap 17 należy oczywiście rozumieć w sensie biblijnym, czyli jako bałwochwalstwo. Jednakże bezpośrednią inspiracją dla obrazu Rzymu jako prostytutki w Ap 17 mogły być monety Wespazjana z motywem Dea Roma, wybite w prowincji Azji w 71 roku, na których widnieje podkasana kobieta z nagimi ramionami, siedząca na siedmiu pagórkach Rzymu. Boginię Romę czczono w tej prowincji gorliwie, a Apokalipsa to jak widać zwalczała. Dodatkowo na monecie spod nóg kobiety wyłania się bóg Tybru o cechach wężowatych, może prawzór głów potwora $\mathrm{z}$ wizji. U stóp pagórków widać wilczycę, łac. lupa - chodzi oczywiście o karmicielkę Romulusa i Remusa $\mathrm{z}$ legendy założycielskiej Rzymu, ale to słowo oznaczało też prostytutkę. Podpis ROMA wyjaśniać może imię z Ap 17,5.

Apokalipsa odwołuje się zatem do kosmologii bliskowschodniej, przedstawiając niebo, ziemię i czeluść. Ożywia znany z archaicznych mitów motyw kosmicznego starcia sił dobra i zła. Korzysta zarazem z wątków greckich: atak potwora na kobietę i nowo narodzone dziecko (Latona i Apollo; Ap 12); cztery żywioły (Ap 16); klucze otchłani (Ap 1,18); symbolika ciał niebieskich (Ap 1,20; $22,16)$. Przedstawia hybrydy zwierzęce, motyw mityczny (choć przejęty z Księgi Daniela).

Wykorzystano je jednak jako przyjęte w ówczesnej kulturze symbole, bez ulegania pogańskim wierzeniom (metoda podobna, jak w Rdz 1-11). Równolegle wykorzystano inne typy popularnej symboliki. Z drugiej strony mitologiczne przedstawienie potworów w Ap 13 dowodzi tendencji do polemiki z mitem, albo też do przewartościowania mitów zastanych, do budowania „nowej

23 S. Witetschek, The Dragon Spitting Frogs: On the Imagery of Revelation 16.13-14, NTS 54 (2008) 4, s. 557-572. 
mitologii”24. Inny przykład polemiki to aluzje do kultu cesarskiego ${ }^{25}$. Ten kult stanowi tło Apokalipsy, ale trudno mówić w tym przypadku o wpływie.

Jeśli chodzi o wpływy filozoficzne, mniej wyraźne, choć postulowane ${ }^{26}$, z platonizmem można wiązać jaskrawe odróżnienie przyszłego, niebiańskiego i świetlistego świata od ziemi (Ap 21). Stoickie przewidywanie co do „zognienia” świata (ekpyrosis) mogło zabarwić zapowiedzi zniszczenia w ogniu. Rygorystyczna etyka Ap 2-3 też może mieć inspirację stoicką, a nazywanie doskonałego „Zwycięzcą” ma odpowiednik u Epikteta (Diatryby 1,18,22). Pitagorejczycy interesowali się symboliką liczb, ważną dla Apokalipsy. Wymieńmy 3 (symbol całości), 4 (świata i sprawiedliwości), 7 (święta i doskonała) i 10 (pełnia); i tu jednak inspiracją dla Apokalipsy mogła być Księga Daniela ${ }^{27}$.

\section{Summary}

Greek influences on the Revelation of John are related to the Hellenistic inspirations of the apocalypticism, which are visible in Daniel and other apocalypses. Their visionary elements and their interest in the future are closer to the Greek perception of the prophecy than to the Hebrew tradition. More detailed influenced can be found in Rev 1.4,8 (description of God); Rev 1.12-20 (Helios imagery, keys, astral symbolism); 666 could result from a gematria. Mythical inspirations include portraying angels and other beings (Rev 6.8; 9.1; 16.4-7; 20.13-14); modeling Rev 12 after the myths on cosmic fight and divine births (especially Apollo and Python); apocalyptic beasts similar to mythical animal hybrids (Rev 13; with Nero redux story and legends on moving statues). Currents opinions on the structures and elements of the world are reflected in Rev 5.13; 16. Platonic, Stoic and Pythagorean inspirations are possible. The author adapted freely pagan imagery, but without modifying his theology.

24 Zob. S.J. Friesen, Myth and Symbolic Resistance in Revelation 13, JBL 123 (2004) 2, s. 281-313.

25 Przegląd badań: M. Naylor, Royal Imperial Cult and Revelation, CBR 8 (2010) 2, s. 207-239.

26 O. Böcher, op. cit., s. 480-488.

27 K. Kiejdo, op. cit., s. 264-269. 